\title{
JUGADORES DE PELOTA MAYA EN TIEMPOS DEL OXLAJUJ B'AK'TÚN
}

\author{
MAYAN BALL PLAYERS AT THE TIME OF OXLAJUJ B'AK'TÚN
}

Jairzinho Francisco Panqueba Cifuentes ${ }^{1}$

\section{Resumen}

\begin{abstract}
La presente reflexión hace parte de un proceso investigativo cuyo objeto ha sido la práctica contemporánea del juego de pelota maya en Guatemala. Es un acercamiento analítico a los testimonios de vida recabados a través de la metodología de investigación-aprehendizaje compartida con los actores del proceso. Sus trayectorias vitales nos permiten comprender en descripciones y acciones, los detalles contemporáneos de una manifestación cultural, lúdica y recreativa ancestral. Pero también de qué maneras el juego de pelota mesoamericano es fuente de conocimientos de los patrimonios corporales hasta ahora difusos entre discursos relacionados con el folclor, las etnicidades, las artes, el deporte, la cultura, las espiritualidades y en general con ciencias como la historia, la antropología y la arqueología. Las vidas cotidianas de los actuales jugadores de pelota ayudan a comprender una parte de las sabidurías ancestrales mayas. Se integran, por tanto, a los testimonios de las herencias inmateriales arqueológicas representadas en los campos de juego de pelota diseminados por Mesoamérica.
\end{abstract}

Palabras clave: Jugadores, mayas, Mesoamérica, chaaj, b’ak’tún.

Abstract

This reflection is part of a research process about the contemporary practice of Mayan ball game in Guatemala. It is an analytical approach to life witness demanded by a learning-research methodology shared with players of the process. Their life paths allow us to grasp through descriptions and actions, contemporary details of an ancient cultural, playful, and leisure expression. Also shows some ways where Central American ball game is a knowledge source of now-blurred tangible assets among discourses related to folklore, ethnicities, arts, sports, culture, spirituality and basic sciences, such as History, Anthropology and Archeology. Currently daily lives of ballplayers help us to understand some of ancient Mayan wisdom. Therefore, they are involved to evidences of archaeological intangible heritage depicted into the ball game fields scattered around Middle America.

Keywords: Players, Mayans, Middle America, chaaj, b’ak'tún.

Fecha de recepción: 18 de mayo de 2012

Fecha de aprobación: 15 de septiembre de 2012

1 Aprehendedor de saberes ancestrales y de la vida cotidiana. Dr. en Ciencias Sociales con espe-
cialidad en Antropología Social del Centro de Investigaciones y Estudios Superiores en Antropología
Social (CIESAS),Guadalajara, Jalisco, México. Mg. En Ciencias Sociales con énfasis en Estudios Étnicos
de la Facultad Latinoamericana de Ciencias Sociales (FLACSO), Ecuador. Lic. En Educación Física por
la Universidad Pedagógica Nacional, Bogotá, Colombia. Catedrático Facultad de Educación Física, Uni-
versidad Pedagógica Nacional. Docente Colegio San Bernardino, territorio muisca de Bosa en Bogotá,
Colombia. Correo electrónico: panqueba@gmail.com. 


\section{Introducción}

Según los conocimientos astronómicos mayas, el oxlajuj b'ak'tún marca el cumplimiento de un quinto ciclo en el tiempo y la consecuente iniciación de uno nuevo, el paso al sexto sol. Este hito cronológico ha trascendido las interpretaciones académicas, científicas, new age y de los sabedores y las sabedoras mayas (Tally, 2011). Pero también ha representado en la vida cotidiana, la oportunidad para promover los distintos legados que los pueblos mesoamericanos han compartido en todas las épocas del mundo.

En este contexto, el chaaj (denominación del juego de pelota maya durante la época posclásica) ha sido objeto de estudio para la arqueología, la historia, la epigrafía y demás ciencias cuyos intereses implican a las sociedades antiguas. Por otra parte, ha habido una inusitada promoción de su práctica a cargo de instituciones y personas que reivindican algunos de los aspectos que abarca el juego. Sus enfoques comprenden varias tendencias que por momentos se funden parcialmente en por lo menos dos crisoles. Uno que contempla el juego desde su dimensión sagrada (Ramírez y López, 2005; Digef, 2010) y otro que lo concibe desde su dimensión agonística-deportiva (Digef, 2010). Como práctica deportiva, el juego de pelota maya presenta un dinamismo expresado en la organización de campeonatos y eventos de competición. Y como juego sagrado es posible distinguir grupos que han intentado re-crear los patrimonios corporales muy ligados a las ceremonias mayas, que paulatinamente han ganado terreno en la actualidad espiritual del mundo.

Las vertientes de re-creación actual del juego obedecen a las distintas perspectivas con las que las personas y organizaciones han puesto a circular los conocimientos ancestrales. Gracias a ello, hoy tenemos certeza acerca de los aportes que las sociedades mayas han hecho desde sus historias y cotidianidades. Por ejemplo, las ancestras $^{1}$ y los ancestros mayas identificaron el número cero (0) como el portador del todo, del fin, de la tranquilidad y de las potencialidades. La semilla y el

1 Es pertinente aclarar que la expresión "las ancestras" hace alusión a los aportes que las mujeres han sumado al devenir cultural de los pueblos. Aunque la palabra "ancestras" no hace parte del diccionario de la Real Academia de la Lengua Española, aquí la utilizamos como reivindicación de la figura femenina. Como ya es sabido, la historia patriarcal ha nominado a las personas y sus producciones desde una perspectiva androcéntrica, cuestión que este trabajo también se ha propuesto evidenciar. vacío que simbolizaron con un glifo que denota la semilla de maíz: ixim.

El vacío que contiene la totalidad no manifestada de todo cuanto existe, se representa por medio del CERO, cuya aceptación maya difiere completamente a la negación absoluta. Por el contrario, da cuenta de una dinámica en estado de quietud, en estado de germen, de un objetivo a cubrir, o de un virtual comienzo formativo donde todo únicamente permanece latente. Asimismo, como todo proceso llega a su culminación, el CERO, también, da idea de terminación. (Matul, 2007, p. 151)

Como sociedades mesoamericanas cultivadoras de la tierra, los pueblos mayas debían poner especial atención a los diversos cambios del clima, de la atmósfera, la duración de los días, las noches y de los periodos solares y lunares. Fue así como los ancestros y las ancestras mayas describieron detalladamente el comportamiento de los astros y los movimientos planetarios. Erigieron observatorios astronómicos en los que se evidencian sus desarrollos matemáticos, filosóficos, astronómicos y religiosos. Sus historias y cotidianidades fueron plasmadas en pirámides, estelas ${ }^{2}$, campos de juego de pelota; muros residenciales, recreativos y ceremoniales. Estos legados nos han comunicado sus cosmovisiones y conocimientos ancestrales.

Entre los legados más importantes de los pueblos mayas tenemos dos calendarios. El de cuenta corta que consta de 260 días, cantidad coincidente con los nueve meses de gestación humana según el calendario gregoriano. Por otra parte, el año solar o calendario de cuenta larga está compuesto por 360 días, periodo conocido como tun (18 winaq). A partir de allí, 20 tun conforman un k'atun, que está compuesto por 7200 días. Un b'ak'tún es la combinación de 20 k'atun, es decir 144 000 días. El conteo solar continúa ascendiendo de manera que 20 b'ak'tun o 2880000 días constituyen un piktun; 20 piktun un kalabtun (57 600000 días) y 20 kalabtun suman un kinchiltun (1 152000000 días). Según la estela "C" del sitio arqueológico de Quiriguá, Guatemala, el día 21 de diciembre de 2012 es el final del b'ak'tún trece (oxlajuj). Este conteo fue iniciado el día cero b’ak'tún, cero k’atun, cero tun, cero winaq. La fecha corresponde en el calendario gregoriano al 28 de agosto del 3114 a.C.; desde ese día hasta el 21 de di-

2 Monumentos tallados en altas piedras por las generaciones indígenas mayas que nos antecedieron. Allí dejaron plasmados varios textos en forma de glifos que datan de alrededor del año 500 a.C. 
ciembre de 2012 habrán transcurrido cinco periodos o soles de 5125 años cada uno.

En el contexto del cambio de era según el calendario maya de cuenta larga, el chaaj como práctica sagrada ha sido decididamente impulsado desde el Ministerio de Cultura y Deportes de Guatemala. Con ese fin conformaron un grupo de jugadores que desde hace poco más de seis años, han estado difundiendo el chaaj como una expresión de lo ancestral puesto en tiempos actuales. Este ha sido uno de los ejes de la investigación que estamos adelantando ${ }^{3}$.

Si bien el presente artículo es un análisis parcial de las informaciones obtenidas durante el proceso de investigación aludido, es un acercamiento que perfila algunas conclusiones. El escrito está distribuido en tres partes, con unas conclusiones parciales. La primera ofrece una perspectiva teórica desde de los nuevos acercamientos al tema étnico. La segunda presenta los detalles metodológicos de los aprehendizajes compartidos con los jugadores. Y la tercera parte es la descripción de las trayectorias de vida de los jugadores, a través de las cuales comprendemos el espacio de acción en que el chaaj converge como expresión del fin de un tiempo para la humanidad, y el inicio de otro.

\section{Patrimonios corporales en tiempos del oxlajuj b’ak'tún}

Como patrimonios corporales concebimos para esta investigación las prácticas, ritos y estéticas asumidas por las personas frente a sus relaciones mutuas y con el entorno. Los patrimonios corporales son una de las tantas formas de expresión de las diversidades humanas. Tales patrimonios están conformados por los juegos ancestrales y sus dimensiones rituales, ceremoniales, lúdicas, deportivas, recreativas e históricas. Son legados inmateriales que las comunidades, pueblos,

3 El trabajo a que hacemos referencia se titula: "Kiq'axan riwach Zepcuagoscua -Chaaj u'wbohiná. Intercambio entre dos juegos ancestrales practicados por los pueblos indígenas de Colombia (tejo chibcha) y Guatemala (pelota maya)". Lo iniciamos en enero de 2010 y actualmente continuamos en su ejecución. Ha sido auspiciado desde Colombia por la Comunidad Intercultural MuisKanoba, la Corporación Ambiental y Empresarial Tingua y la Asociación Artística, Cultural y Deportiva Cuza Bague. Y desde Guatemala hemos recibido el apoyo del Ministerio de Cultura y Deportes, además de otras personas que se han estado vinculando de manera paulatina: Jorge Mario López Tista, Elder Aceytuno, Erwin Castro Mulul y Luis Chutá, entre los más cercanos al proceso. familias y personas practican actualmente. Para llegar a esta definición, es pertinente la apropiación del concepto de cultural corporal, el cual entendemos como:

La manera contundente en que cada estructura social y cultural ha marcado al cuerpo; ello connota un concepto de éste último, que ha desbordado a la organicidad y ha comprometido al entorno que lo acuna. Entre cuerpo y cultura se ha generado una relación en la que ambas partes se han permeado y se han co-construido, lo que ha dejado improntas susceptibles de rastrear; ha interesado aquí, desde el cuerpo, caracterizar la cultura en su matriz identitaria. El cuerpo, en este caso, ha estado expresando el paso de la cultura y su diario acontecer en: percepciones, actitudes, prácticas y representaciones. (Arboleda, 2009, p. 3)

Pero además de esta concepción, también es pertinente citar los referentes materiales que nos llevan a evocar lo simbólico. Tal vez este sea un sendero para analizar la manera como en los tiempos actuales, al lado del desconocimiento de quiénes somos y de cómo hemos evolucionando, se detecta una "búsqueda en las raíces". Es la descripción de un constante reencuentro con "lo propio" y con lo que puede identificar a una persona en el contexto donde se mueve. Es un despertar ante la creencia de los pueblos sin identidad. Premisa que Eric Wolf (2005) trabajó bajo la idea de "gente sin historia", en el contexto del dominio de Europa.

Una de las maneras en que contemporáneamente damos cuenta de este fenómeno, es el mercadeo ahistórico propuesto desde instancias gubernamentales. "Somos el mundo maya" es el título de una noticia en un diario de circulación nacional en Guatemala (Prensa Libre, 2012). Esta frase fue expresada por el director del Instituto de Turismo de Guatemala (Inguat) durante una entrevista. En dicha intervención, el funcionario manifiesta que: "Guatemala emprendió el lunes último su campaña para promocionarse como destino turístico por la celebración del cambio de era maya, el próximo 21 de diciembre" (Ídem.). Enseguida, los argumentos del funcionario dejan entrever la percepción institucional, pero también mayoritaria del Estado frente a su propia historia:

La campaña está basada en el eslogan '2012 no es solo una fecha, es un lugar, es Guatemala'. Es una campaña de pertenencia, de entender que Guatemala es el corazón del mundo maya, y es aquí donde tenemos la estela que documenta el 13 baktún con el cambio de era. Hay países que se están apropiando del tema. (...) Países alrededor, como 
México, El Salvador y Honduras, lo que quieren es apropiarse del tema maya como civilización, claro, muy a su conveniencia. El turista termina reconociendo que si quiere conocer a los mayas tiene que venir a Guatemala. (...) La inversión suma US\$3 millones -Q24 millones-. El presupuesto de Q52 millones para el mercadeo de este año se enfoca para la ocasión del cambio de era maya, combinado con el resto de ejes turísticos. Se promociona en cuatro áreas: turismo interno, regional en Centroamérica, Norteamérica y Europa. (Prensa Libre, 2012, p. 40)

Desde la perspectiva institucional, es evidente que la cercanía del oxlajuj b'ak'tún representa una urgencia de promoción turística que espera réditos económicos. Esto no quiere decir que para la gente maya tampoco sea de esta manera. Lo que realmente se pone de manifiesto es el poder de las élites -en este caso institucionales- en el neo-acercamiento posmoderno a "lo indígena". Este es el contexto de emergencia cultural en el que el juego de pelota maya se encuentra (Panqueba, 2011). En este mismo sentido, las búsquedas trascendentales de "lo humano" han hecho de los sitios arqueológicos una incubadora de mercadeo paralelo. Los shows ofrecidos en los hoteles más costosos de la Riviera Maya (estado de Quintana Roo, México), Tikal (departamento del Petén, Guatemala) y otros cercanos a los sitios arqueológicos dan cuenta de ello.

El mercado turístico actual en torno a "lo étnico" se distingue por acudir a expresiones simbólicas como el esoterismo, el neo-chamanismo, las manifestaciones new age y las tendencias ecologistas. Sus manifestaciones objetivas han alimentado los discursos que, por lo menos en las últimas dos décadas, han ensalzado "lo indígena". Esto puede leerse de acuerdo a la experiencia de los discursos neo-indigenistas en las ciudades (Sarrazín, 2008). Pero también desde algunas tendencias de la antropología que se han ocupado de la génesis de formas culturales basadas en la capacidad humana para crear símbolos (Wolf, 2005).

Dado que el simbolismo entra en la definición misma de sociabilidad humana, así también los seres humanos de cualquier parte han unido estas construcciones básicas de 'naturaleza' humana con sus construcciones de naturaleza y supernaturaleza circundantes (p. 118). Es el caso de los campos de juego de pelota construidos en Mesoamérica por varias generaciones. Estos escenarios datan aproximadamente del año 500 a.C. (Digef, 2010 p. 16). Y según las investigaciones arqueológicas, la práctica del juego de pelota se remonta hasta unos 2500 años a.C. (Ibíd., p. 13-15). Los campos de juego hacen parte a su vez de grandes complejos construidos con fines residenciales, religiosos, recreativos y en general para el desarrollo de la vida cotidiana ancestral. Están imbricados con las estructuras de templos y graderíos para la contemplación, sin duda, de espectáculos milenarios.

Estos escenarios constituyen un referente material en el que usualmente tienen lugar las simbiosis de las tendencias new-age con las que portan los herederos y las herederas directas de los distintos pueblos indígenas del mundo (Tally, 2011). El argumento de cierre para la información brindada por el funcionario del Inguat refleja esta posición:

Invitamos al Foro Permanente de Expertos de Pueblos Indígenas de las Naciones Unidas a que realicen en el país, el 21 de diciembre, su reunión anual preparatoria para su asamblea general. Además, Guatemala fue nombrada 'La capital mundial de la Filosofía por parte de la UNESCO. (Prensa Libre, 2012 p. 40)

Si bien este es un fenómeno de la llamada globalización, en tanto "lo étnico" emerge como fenómeno de moda, paradójicamente está produciendo individualidades solitarias. Es una manifestación de la modernidad líquida que rescata identidades, pero también recrea identificaciones (Bauman, 2003). Estas formas de engullir identidades, tanto la institucional como la individual, son características de la posmodernidad. Son una manifestación de un fenómeno que el antropólogo mexicano Héctor Díaz Polanco (2006) describió como la etnofagia (Díaz Polanco, 2006; Patzi, 1999). Este término, acuñado desde la década de los años noventa del siglo XX, se ha usado para denotar las formas en que el capitalismo neoliberal alimenta su funcionamiento a partir de la presencia de diversidades étnicas en sus contextos de intervención. Con la etnofagia:

No se busca la destrucción mediante la negación absoluta o el ataque violento de las otras identidades, sino su disolución gradual mediante la atracción, la seducción y la transformación. Por lo tanto, la nueva política es cada vez menos la suma de las acciones persecutorias y de los ataques directos a la diferencia, y cada vez más el conjunto de los imanes socioculturales y económicos desplegados para atraer, desarticular y disolver a los grupos diferentes. (Díaz Polanco, 2006 p. 161)

Pero no existiría una forma universal de etnofagia. Por ejemplo, Félix Patzi define la etnofagia estatal como 
"proceso de etnocidio cultural, por medios más simulados y a largo plazo" (Patzi, 1999 p. 537). La etnofagia también ha sido una estrategia que consiste en:

(...) el abandono de los programas y las acciones explícitamente encaminados a destruir la cultura de los grupos étnicos y, en cambio, la adopción de un proyecto de más largo plazo que apuesta al efecto absorbente y asimilador de las múltiples fuerzas que ponen en juego el sistema. (Díaz Polanco, 2006, p. 160)

La etnofagia promueve la integración y la asimilación de las poblaciones étnicas que hacen parte de un Estado-nación. Como promoción hecha a través de métodos "respetuosos" de los derechos humanos, el proceso etnofágico es una característica del modelo multiculturalista frente a los patrimonios: tolerante con las diversidades occidentales-liberales-capitalistas. Pero de acuerdo a los usos de las diversidades que realizan algunas personas y grupos, indígenas y no indígenas, la etnofagia también puede ser una estrategia desde discursos altermundistas. Unos hacen de "lo étnico" su forma de vida, fortaleciendo la conciencia y acciones para con los pueblos, familias y personas indígenas. Pero otros mantienen manejos ambiguos o "usos de la diversidad" (Geertz, 2001, pp. 65-75) que unas veces se tornan en esencialismos culturales, otras veces en posiciones relativistas, y otras veces en "anti-antirrelativistas" (Geertz, 2001, p. 91). Unos y otros manejos pueden ser leídos desde la perspectiva de los patrimonios inmateriales como usos de las identidades indígenas: esencialismos estratégicos (Spivak, 1985).

En la perspectiva de los esencialismos estratégicos, las instituciones son lugares para indagar por unos y otros usos. Si bien son usos tal vez derivados de procesos etnofágicos, no dejan de ser estratégicos y, en consecuencia, de presentar niveles de acción más que de simbolismo. De allí el interés reflexivo por las etnofagias en esta investigación. Un campo en el que los patrimonios se movilizan como simbólicos cuando es necesario de manera coyuntural, pero en el que las acciones son razón de ser. Este es el contexto en el que se hallan los patrimonios corporales en torno al juego de la pelota maya, en tiempos del oxlajuj b’ak'tún.

\section{Senderos de los jugadores del oxlajuj b’ak'tún}

Aunque el universo de personajes directamente implicados en el grupo de jugadores es de ocho, solo cuatro establecimos una común-unidad de especulaciones ${ }^{4}$. Nos condujimos así a comunicar los temas del presente artículo por tres motivaciones: los temas tratados en conversaciones espontáneas, las memorias cotidianas captadas en el hacer propiamente dicho del juego, y por los acercamientos a nuestras mutuas experiencias de vida. Estos tres senderos fueron motivando los contactos con otras personas del medio deportivo, artístico y organizativo maya e institucional. Así, fuimos ampliando las perspectivas de búsqueda en material bibliográfico y en las bibliotecas de los patrimonios materiales mesoamericanos: los lugares sagrados y sitios arqueológicos. No aparecen explícitos muchos detalles de este entramado de relaciones porque quisimos priorizar detalles personales con respecto a la práctica del juego. Ello dentro del contexto del fin e inicio de dos épocas en el conteo del tiempo del calendario maya de cuenta larga.

Para organizar los testimonios y experiencias fuimos re-creando las formas priorizadas por los ancestros y las ancestras mayas para recopilar sus memorias cotidianas. Los objetos de uso diario dan cuenta de ello: vasijas de arcilla, cuchillos de obsidiana, utensilios en piedra y demás elementos nos han permitido conocer las ocupaciones de los pueblos ancestrales. Sin embargo, el medio fundamental por el cual hemos sabido y seguido cronológicamente los pormenores y eventos de las sociedades mayas han sido sus construcciones.

En los muros, techos y pisos de sus pirámides podemos encontrar explícitos varios relatos, biografías, cosmovisiones y procedimientos seguidos en caso de algún evento extraordinario. Pero aunque estas informaciones han podido parecer solo hechos decorativos o artísticos para ciertas tendencias interpretativas de la arqueología, hay otros medios que fueron producidos para comunicar a las generaciones siguientes cada hecho acaecido en territorios mayas. Refiero específicamente a las estelas que nos informaron sobre el oxlajuj b'ak'tún, pero también sobre la práctica del juego de pelota. Es el caso de la estela del juego de pelota maya de Quiriguá, Guatemala, descubierta el 12 de agosto de 2010.

Arqueólogos del Parque Quiriguá anunciaron un descubrimiento fuera de lo común: un friso único en su tipo en el área que muestra la imagen de dos nobles -o el que podría ser un gobernante y un no-

4 El autor del presente texto hace parte del grupo de jugadores, por ello en este apartado la redacción priorizada es en primera persona. 
ble- enfrascados en el juego de pelota mientras dos mujeres, detrás, los observan en posición sumisa. El hallazgo corresponde al Panel 1 de Quiriguá descubierto en el grupo Este, un conjunto formado por 3 estructuras. Este grupo de monumentos había sido mencionado desde 1894 por el investigador Alfred Maudslay. (El Periódico, 2011)

Siete meses después, del 20 al 24 de marzo de 2011, durante la celebración del equinoccio de primavera en los sitios arqueológicos de Uaxactún y Yaxhá (Guatemala), la imagen fue vista por primera vez en el tablero de juego (Ilustración 1$)^{5}$. Los cinco participantes dedicamos los dos meses precedentes a reproducir la imagen de la estela de Quiriguá. Así, esta forma de re-crear y aprehender los patrimonios ancestrales empezó a hacer carrera como metodología también de investigación.

\section{Ilustración $1^{6}$}

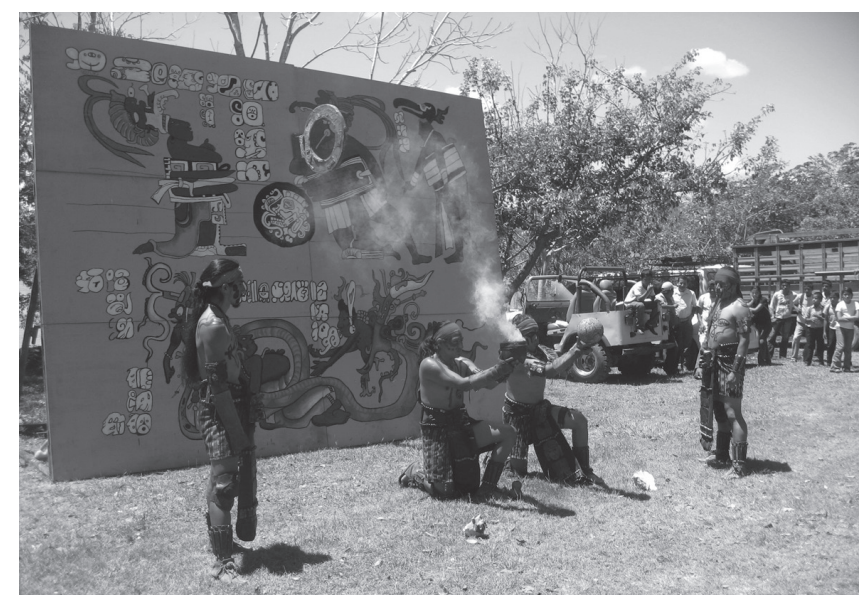

La metodología de indagación para conversar sobre las subjetividades en el chaaj, han sido las memorias cotidianas captadas a través de video, fotografía y audio que en cada juego se recogen. El uso de estas tecnologías permitió la reproducción más expedita y ágil posible del friso en el tablero de juego. Para la escritura del presente artículo, revisamos con el grupo de jugadores un número aproximado de 3000 fotografías, 50 videos y 10 relatos en torno al chaaj. Con las contemplaciones del material fue-

5 El juego propiamente dicho se efectúa contra el tablero, frontón o muro de madera. Este elemento consta de un cuerpo desarmable, conformado por seis piezas de madera y soportes metálicos en la parte posterior. Mide aproximadamente cinco metros de largo por tres de alto. En la parte superior que divide el tablero en dos, se dispone un aro de metal sujetado a la estructura (Panqueba, 2011).

6 Foto archivo Micude, 2011. Jugadores de pelota a orillas del lago de Yaxhá, durante el día del agua, 2011. ron fluyendo anécdotas, relatos relacionados, preguntas y ninguna respuesta. Cada contemplación nos fue llevando a descripciones que abarcaron la oralidad en los idiomas mayas y en español, pero también a descripciones corporales, evocando momentos específicos de algún juego.

En un artículo anterior (Panqueba, 2011) contemplamos parcialmente los ambientes inmediatos que corresponden a la práctica contemporánea del chaaj. En esta oportunidad, acudimos a los jugadores, ramas visibles y floridas de los árboles ancestrales que como la ceiba, contienen las sabidurías de los tiempos de las que nos hablan legados patrimoniales materiales como el libro del Pop Wuj.

El árbol es el más claro ejemplo de la rapidez con que se lleva registro de millones de unidades de cualquier cosa, demuestra que es la manera más eficiente de trasladar algo desde un lugar hasta muchos otros sitios. El árbol tiene la forma que tiene porque es la mejor para recoger la humedad del terreno a través de sus diez mil raicillas y distribuirla velozmente a sus diez mil hojas. (Matul, 2007 p. 156)

Compartir las ofrendas testimoniales sobre las subjetivaciones que describen los jugadores de pelota maya contemporáneos es hacer historia del presente. Aunque para referirse al pasado es recurrente buscar a personas de la tercera edad, en este caso la creencia es revertida. Los jóvenes jugadores de pelota maya, si bien son ramas del tronco maya, crecen como las raíces milenarias de los territorios mesoamericanos. En sus cotidianidades, discurso y relaciones interétnicas, son evidentes los enlaces recurrentes con las ancestralidades. Para hablar con los mayas jugadores de chaaj, muchas veces la entrevista, la narración anecdótica o la conversación biográfica son insuficientes. Sin asistir, participar e inmiscuirse en los actos cotidianos es imposible adentrarse en las raíces de esa gran ceiba que representa los conocimientos, ciencias, artes, usos y saberes.

\section{Los jugadores del oxlajuj b’ak'tún}

El perfil de los jugadores de pelota maya del Micude es el de jóvenes entre los 25 y 30 años de edad. Algunos cursando una carrera universitaria y otros con estudios truncados debido a las situaciones que obligan a elegir un trabajo a cambio de la formación profesional. Jugando con ellos he dado cuenta del significado específico del término "re-creación" en el contexto del oxlajuj b’ak'tún descrito en páginas anteriores. La transformación de ciudadano común a jugador sucede más que por el atuendo y pinturas corporales, por la 
convicción que como lazo comunicativo ha operado entre las raíces y las ramas del árbol.

Aunque previamente a su desempeño laboral en el Ministerio ninguno había tenido un acercamiento a la práctica del chaaj, hubo detalles que paulatinamente fueron llamando la atención de los jóvenes. Keme, el más antiguo de ellos, hizo parte del grupo inicial que a través del programa de juegos tradicionales del Micude, empezó a exhibir el juego de pelota maya en el año 2006. Los primeros jugadores convocados por el entonces coordinador del programa, trabajaban en otras áreas del Micude. Tan solo Keme y el coordinador eran mayas, otros tres integrantes eran ladinos (categoría étnica de uso generalizado en Mesoamérica para identificar e identificarse mestizo).

Con los años fueron sucediéndose ajustes operativos, administrativos y de utilería, a la par de lo propio con la rotación de miembros del grupo. Paulatinamente los jugadores de pelota maya llegaron a ser en su totalidad miembros de diferentes grupos lingüísticos de etnia maya. Cuando nos conocimos con sus miembros en el año 2011, tres jugaban y uno cuarto coordinaba y hacía la narración durante las presentaciones. Dado que en el campo siempre hacía falta un jugador, fui invitado a participar. El esquema actual del grupo es similar, aunque el Micude ha contratado jugadores para conformar dos equipos. Esto para atender la demanda del programa "Viajes al mundo maya” (Ilustración 2), en el marco de los eventos preparatorios al 21 de diciembre (Prensa Libre, 2012).

Ilustración $2^{7}$

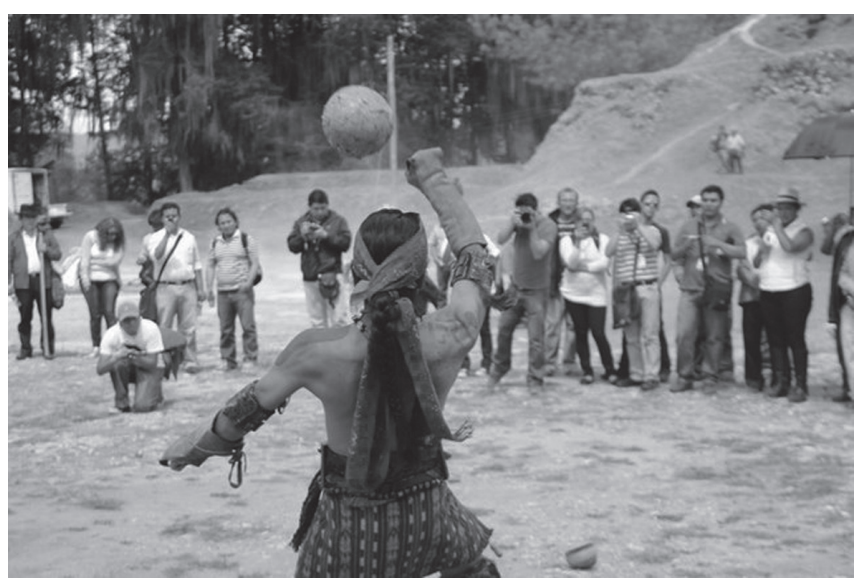

7 Imagen de archivo del Ministerio de Cultura y Deportes, captada durante la presentación del programa "Viajes al mundo maya". Gumarkaaj, Santa Cruz del Quiché, Guatemala. Marzo 15 de 2012. La imagen capta un pasaje de la participación como jugador por parte del autor del presente artículo.
Además de Keme, han sido Mulul y Chutá los compañeros de juego, contemplaciones, especulaciones y aprehendizajes. La polifonía obtenida con sus cotidianidades es la que ha permitido re-crear el juego ancestral en su dimensión de patrimonios corporales. Ellos re-crean el juego ancestral que, por excelencia, es portador patrimonial de sus raíces mayas. Y así lo dejan sentir, saber y ver cuando conversan, entrenan y se presentan como jugadores.

Para Mulul, la particularidad que le atrajo a formar parte del juego fue el "compañerismo" que percibió en el grupo. Ello da señales de una distinción entre las actividades recreativas, deportivas y lúdicas, con la del juego de pelota. Y si bien la experiencia previa de este jugador con el chaaj se limitaba a haber visto una película que llevó por título para Latinoamérica "El camino hacia El Dorado", logró adaptarse al juego y superar incluso una lesión corporal que le había afectado recientemente. El fenómeno de las películas con tramas étnicas hacia el fin de siglo XX, ha influido notoriamente el actual estado de emergencias étnicas en el mundo. Tanto para jugadores como para funcionarios y público asistente a las presentaciones, la imagen más reciente de "los mayas" ha sido la cinta dirigida por Mel Gibson, "Apocalypto" (2006). Película que fue duramente cuestionada por los anacronismos y otros desfases mostrados. En el caso de la cinta evocada por Mulul, según su versión ni en su educación primaria, ni secundaria o universitaria había sentido tan cercano el juego de pelota maya ${ }^{8}$.

Por otra parte, para Chutá el juego de pelota ha sido una escuela en la que varios episodios le han confrontado con su identificación maya. Uno de esos momentos ha sido el del manejo del idioma. Chutá dice comprenderlo pero no hablarlo. Durante las presentaciones, sobre todo en el momento de la invocación previa al juego, los jugadores deben expresar algunas frases en su idioma. Esto ha representado un reto para Chutá, un momento de reflexión para Keme y un deseo de estudiar su propio idioma para Mulul.

8 Este film de dibujos animados, cuyo título original es "The road to El Dorado", con la dirección de Eric Bibo Bergeron y Don Paul, fue estrenada en el año 2000, pero Mulul la vio cuando transcurría el año 2002. El tema de las películas con temas étnicos, ecologistas y otros de este corte, abre un camino interesante de análisis para el mundo de los estudios cinematográficos, pero también puede ser un objeto de estudio trascendente para las ciencias sociales. 
Respecto de su habilidad innata para dibujar, Chutá manifiesta que otra forma de re-crear las ancestralidades la ha conseguido al expresarse gráficamente en los trazos corporales. La sensación de describir los nahuales y otros trazos, evocados de los cientos de materiales escritos legados por los ancestros y la ancestras, es para él indescriptible. Cada juego es para él un ofrecimiento para el beneficio suyo o de alguien cercano. Cuando ofrenda el fuego es el momento en que ofrece y pide, tal como frente a los altares lo hacen los aj'quij (guías espirituales mayas). En cierta ocasión Chutá se lesionó una mano durante la presentación del juego. Su mejoría fue entonces objeto de petición al abuelo fuego, ofreciendo a cambio todas las energías derivadas de hacer un bonito juego. Trascendiendo el simple enfrentamiento agonístico entre dos fuerzas, las experiencias de Chutá nos llevan a corroborar que:

Todo en el juego de pelota es movimiento y equilibrio. Los cuatro jugadores, los cuatro puntos cardinales del universo, se mueven incesantemente de un lado al otro, brincan, se agachan, suben, bajan, hacen movimientos de rotación y traslación, giran sobre sí mismos. La pelota igual o aún más intensamente gira, golpea, sube y baja, gira sobre sí misma. El caucho sagrado va del cielo a la Tierra, de jugador a jugador, los rincones del universo, de pared a pared, figurando el movimiento, el desplazamiento astral, el gran equilibrio y las energías universales. (Cabrera, 2007 p. 332)

\section{Ilustración $3^{9}$}

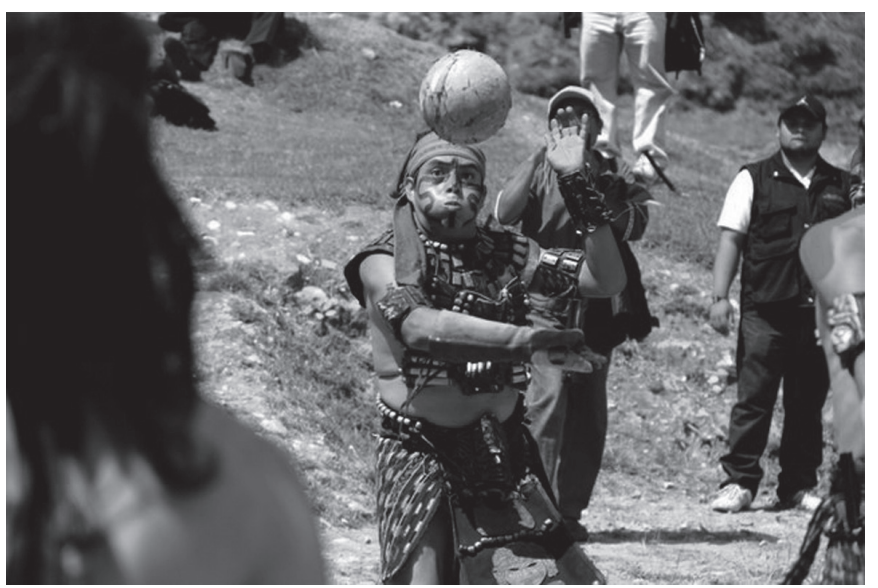

9 Imagen de archivo del Ministerio de Cultura y Deportes, captada durante la presentación del programa "Viajes al mundo maya". Gumarkaaj, Santa Cruz del Quiché, Guatemala. Marzo 15 de 2012. La imagen capta en momento en que Luis busca sus mejores movimientos durante las presentaciones.
Para Keme, cada juego es una oportunidad de "darlo todo", según sus palabras. Es momento para esforzarse al máximo, compartiendo de la mejor manera posible los movimientos corporales en cada uno de los momentos. Durante la invocación al fuego, previa al juego propiamente dicho con la pelota, la concentración es máxima. Y la evocación de todas las personas que le han aportado como jugador de chaaj aparece. Por línea directa, cada raíz del árbol ancestral es convocada para ayudar a mostrar los mejores golpes. Un rito que Keme pone en práctica en cada juego es que el primer contacto con la pelota ha de hacerlo con un golpe de cintura. Una fotografía suya haciendo este gesto corporal ancestral circula en imágenes promocionales, redes sociales, en la portada de un libro (Digef, 2010) y en una re-creación efectuada por artesanos en un barrilete gigante (Ilustración 4).

Ilustración $4^{10}$

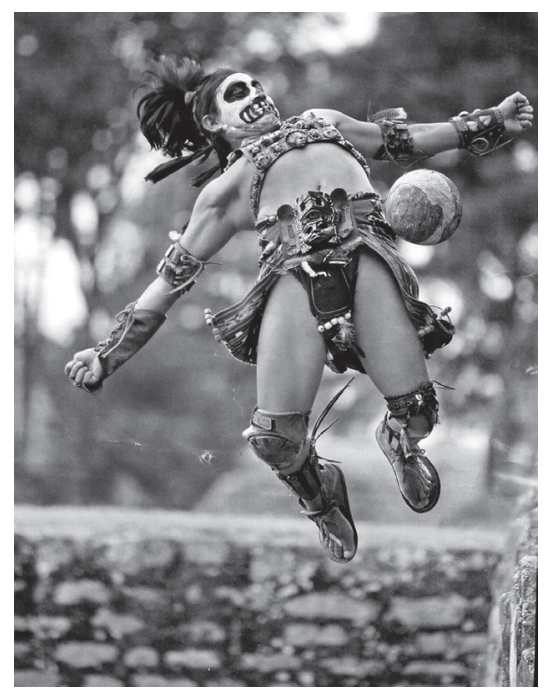

Sin embargo, es importante cuando Keme habla de una ambivalencia sobre su experiencia subjetiva como jugador. Por un lado dice sentirse incómodo y a veces mal. Por otro lado dice sentirse satisfecho y con ánimos de continuar. La incomodidad aparece pese los debidos permisos que solicita a los abuelos y a las abuelas antes de ofrecer una presentación. Siente a veces como si estuviera entregando su cultura a cambio de su salario como jugador. Esta preocupación activa la conciencia para cada momento de los que conforman las acciones del juego. Su relato de cómo fue haciéndose jugador así lo corrobora. El esfuerzo personal por entrenarse en la

10 Esta fotografía fue publicada en noviembre de 2010 en la Revista D, que circula los domingos como suplemento del diario Prensa Libre. La locación es el sitio arqueológico de Iximché, Guatemala. Autor: Derlis Castillo. 
adquisición de habilidades "artísticas", "escénicas", así como la parte "técnica" de gestos como el golpe con la rodilla y con la cadera, son expresiones de su deseo por trascender la escena hacia un ejercicio pedagógico. La mayor satisfacción, dice él, es ver como los niños y las niñas en muchas presentaciones se acercan a preguntar y a jugar. Los aplausos y alegrías expresadas por el público cuando contemplan los movimientos del juego, comunican a los jugadores un resultado favorable a su objetivo de "agradar". Esa es la manera en que la preocupación por una supuesta manipulación de la cultura de los abuelos y de las abuelas queda resuelta.

Para Keme, su mayor logro y anhelo de siempre es una raya impulsada con la cintura. Un movimiento complejo, lírico, exacto y preciso. Esta es su manera particular de re-crear los patrimonios corporales de sus ancestros en la dirección de re-crear pedagógicamente el juego. Personalmente tuve que practicar muchas veces de manera individual este golpe. Jamás logré conseguirlo, aun con la ayuda de quien mejor he visto que lo hace. Y pasados casi quince meses de haberme convertido en jugador, durante una práctica rutinaria, Keme me convidó a ensayar el movimiento. Tras intentarlo varias veces el logro al fin fue concedido. Este episodio ilustra mucho más el argumento de Cabrera (2007) antes citado, respecto a las energías de los movimientos y su similitud con las dinámicas astrales. En lo subjetivo cada persona lo percibe estando transformado en jugador, durante ese momento ritual que es el juego. Así lo dejábamos entrever en la entrega anterior sobre el tema (Panqueba, 2011): la sacralización conseguida a través de la indumentaria, el maquillaje corporal y la invocación solo se materializa para trascender lo simbólico durante la acción misma del juego.

\section{Conclusiones}

Los actuales jugadores de pelota maya del Ministerio de Cultura y Deportes de Guatemala trabajan en un área específica dedicada a los "juegos tradicionales". Desde allí son responsables de hacer presentaciones de juegos y participar en eventos recreativos para la difusión y promoción de la actividad física en general. Pero en su papel de ramas del árbol milenario portador de los patrimonios corporales de raíz maya, son responsables de re-crear para sí y para quienes les observan, el mundo maya desde una dimensión en la que no es costumbre presentar "lo maya".

En las versiones de los jugadores actuales, sus presentaciones son tomadas como un hecho re-creativo. $\mathrm{Al}$ respecto manifiestan que no salen a ganar o perder sino a dar lo mejor de cada uno. Si bien desean marcar rayas (así se denominan los tantos conseguidos al atravesar la pelota por entre el aro ubicado en la parte superior del tablero), ello más bien obedece a la imagen que quieren proyectar. Esa es la alegría que quieren comunicar; la perciben en los aplausos, voces y celebraciones cuando anotan. Es la alegría del movimiento en equilibrio, la energía del cero en acción. Y la energía del cero que se suspende temporalmente mientras viene un nuevo juego para re-hacer y re-crear. Esa concepción es evidente en cada juego, pero es resultado de las trayectorias vitales de cada jugador. Es por ello que sus testimonios son corazón para comprender el juego de pelota maya en tiempos del oxlajuj b'ak'tún.

El acercamiento de interculturalidades propuesto en esta investigación, es una estrategia para percibir en las diversidades las oportunidades que ofrecen, sin quedarse en su mero reconocimiento. La idea central ha sido el estudio de las prácticas históricas y cotidianas, enmarcadas en el pluralismo de los patrimonios corporales. La importancia del tema en nuestro tiempo se fundamenta en que apenas contamos con una parte de datos sólidos sobre los hechos que han marcado nuestro presente. Como informaciones, han sido examinadas desde varias perspectivas científicas, permitiendo disímiles aprovechamientos. Pero también han creado una ausencia analítica acerca de las formas cotidianas en que vivimos estos legados ancestrales

\section{Referencias}

Arboleda, R. (2009). Cultura corporal: miedo, identidad y resistencia. En: VIII Reunión de Antropología del Mercosur (RAM). "Diversidad y poder en América Latina". Buenos Aires, Argentina, 29 de septiembre al 2 de octubre de 2009. Disponible en: http://www.ram2009. unsam.edu.ar/GT/GT\%205\%20\%E2\%80\%93\%20 Corporalidad $\% 20 y \% 20$ Subjetivaci $\%$ C3\%B3n $\% 20$ en $\% 20$ el $\% 20$ mundo\%20 contempor $\%$ C3\%A1neo/ GT\%205-Ponencia\%20[Arboleda].pdf (Último acceso: mayo 10 de 2012).

Bauman, Z. (2003). Modernidad líquida. Buenos Aires: FCE.

Cabrera, E. (2007) [1992]. Cosmogonía maya. En: D. Matul y E. Cabrera, La cosmovisión maya, Tomo I. Guatemala: Liga maya.

Díaz-Polanco, H. (2006). Elogio de la diversidad: globalización, multiculturalismo y etnofagia. México: Siglo XXI.

Digef. (2010). Chaaj. Los ancestrales juegos de pelota maya. Orígenes, significado y orientaciones metodológicas para su enseñanza-aprendizaje en el sistema educativo nacional. Gobierno de Guatemala, Ministerio de 
Educación. Dirección General de Educación Física (Digef). Documento disponible en: http://digef.edu.gt/ biblioteca/pages/libros/Pelota_Maya.pdf.

El Periódico. (2011). Descubren friso con escena de juego de pelota. El Periódico, 9 de marzo del 2011. Disponible en: http://www.elperiodico.com.gt/ es/20110309/pais/192126/ (Último acceso: mayo 18 de 2012).

También disponible en: http://www.historiayarqueologia.com/profiles/blogs/arqueologos-descubrenuna-3 (Último acceso: mayo 17 de 2012).

Geertz, C. (1996). Los usos de la diversidad. Barcelona: Paidós

Matul Morales, D. (2007) [1996]. Fibras del corazón. Sentimiento maya. En: D. Matul y E. Cabrera. La cosmovisión maya, Tomo I. Guatemala: Liga maya.

Panqueba, J. (2011). Chaaj (Juego de pelota mesoamericano): Un juego ancestral entre emergencias culturales. Lúdica Pedagógica, Revista de la Facultad de Educación Física, $\mathrm{N}^{\circ}$ 16. V.2., 44-52. Bogotá: Universidad Pedagógica Nacional.

Patzi, F. (1999). Etnofagia estatal. Modernas formas de violencia simbólica (Una aproximación al análisis de la reforma educativa). Boletín del Instituto Francés de Estudios Andinos, 28(3), 535-559. Disponible en: http://www.ifeanet.org/publicaciones/boletines/28(3)/535.pdf (Último acceso: mayo $18 \mathrm{de}$ 2012).

Prensa Libre. (2012a). Ejecutivo presenta proyecto turístico. Prensa Libre, viernes 16 de marzo de 2012. Guatemala: Casa editora Prensa Libre. Disponible en: http://www.prensalibre.com/noticias/ comunitario/Ejecutivo-presenta-proyecto-turistico_0_664733549.html (Última consulta mayo $18 \mathrm{de}$ 2012).

Prensa Libre. (2012b). Somos el mundo maya. Prensa Libre, jueves 17 de mayo de 2012. p. 40. Guatemala: Casa editora Prensa Libre.

Ramírez Torrealba, E. y Torres D’amico, R. (2005). Una mirada al juego de pelota maya como mito mágico religioso. efdeportes.com, revista digital, Buenos Aires, Año 10, $\mathrm{N}^{\circ} 85$, junio de 2005. Disponible en: http:// www.efdeportes.com/efd85/maya.htm (Último acceso: mayo 18 de 2012).

Sarrazín, J.P. (2008). La "espiritualización" de los discursos neoindigenistas en Colombia. Trace [En línea], 54, 2008, Puesto en línea el 24 de julio de 2009, Consultado el 12 de enero de 2012. Disponible en: http:// trace.revues.org/index $470 . \mathrm{html}$

Spivak, G. (1985). Estudios de la subalternidad: deconstruyendo la historiografía. En S. Rivera Cusicanqui y R. Barragán (Comps.), Debates post coloniales: una introducción a los estudios de la subalternidad. La Paz, Bolivia: Ediciones Aruwiyiri, Editorial Historias.

Tally, E. (2012). Las interpretaciones new age y mayas del oxlajuj b'aqtun. Documento digital acce- sible en: http://es.scribd.com/doc/77675918/ Las-interpretaciones-New-Age-y-mayas-del-oxlajujb\%C2\%B4aqtun-2012-por-Engel-Tally (Última consulta: mayo 18 de 2012).

Wolf, E. (2005) [1987]. Europa y la gente sin historia. México: Fondo de Cultura Económica. 